\title{
Los nuevos frutos de oro. Aparato productivo de piña y naranja en la Zona Norte, Costa Rica (1974-2015)
}

Recibido: 11 de junio 2017

Revisado: 7 de agosto 2017

Aprobado: 27 de septiembre 2017

Luis Diego Arias Campos

Costarricense. Estudiante de Ingeniería en Ciencias

Forestales y de Historia. Investigador en Construcción Organizativa Socio Ambiental,

Universidad de Costa Rica. Correo electrónico: luisdiegoarias93@gmail.com

Juan Manuel Retana Céspedes

Costarricense. Licenciado en

Economía y estudiante de

Historia. Investigador en

Construcción Organizativa

Socio Ambiental, Universidad

de Costa Rica y profesor universitario.

Correo electrónico:

jmretanac@gmail.com

Daniel Torres Sandí Costarricense. Estudiante de Sociología y de

Administración Pública. Investigador y coordinador en

Construcción Organizativa Socio Ambiental, Universidad de Costa Rica.

Correo electrónico: tsdaniel22@hotmail.com

Lidia Peña Rivera Costarricense. Estudiante de Sociología. Coordinadora en Construcción Organizativa Socio Ambiental, Universidad de Costa Rica. Correo electrónico: liberlu09@gmail.com
Resumen: Se analiza la evolución piñera y naranjera en la Zona Norte Norte, mediante la construcción del aparato productivo mediante la prosopografía y la metodología relacional de los derechos humanos. El modelo de desarrollo implementado desde los ochenta ha facilitado la instalación de compañías agroindustriales para la exportación, con unos US\$101 millones de naranja y unos US $\$ 800$ millones de piña para 2015 , principalmente en el norte, y acumuladas en pocas élites-personas con gran influencia política y económica. Esto incide para que esta sea una de las zonas agroindustrialmente más productivas y, al mismo tiempo, una de las de mayor desigualdad y pobreza. Se vuelve necesario enfrentar las adversas situaciones con acompañamientos alternativos ligados a la autonomía alimentaria y laboral.

Palabras clave: agroindustria; explotación laboral; desigualdad; despojo, monocultivo

The new golden fruits. Production of pineapple and orange in the North Zone, Costa Rica (1974-2015)

Abstract: The pineapple and orange development in the North North Zone is analyzed through the construction of the productive apparatus through prosopography and the relational methodology of human rights. The economic model implemented since the 1980s has facilitated the installation of transnational agribusiness companies for exports, with about US\$101 million of orange and US\$800 million of pineapple in 2015, mainly in the north and accumulated in few elites- People, with great political and economic influences. It implies that this is one of the agro-industrially most productive areas and at the same time one of the most inequitable and poverty-stricken areas. It becomes necessary to face the adverse situations with alternative accompaniments linked to food and labor autonomy.

Key words: agroindustry; labor exploitation; inequality; despoiling; monoculture 
1. Esta investigación es parte del colectivo Construcción Organizativa Socio Ambiental (COSA), colectivo que surge gracias al desarrollo de un proyecto de organización comunitaria en Caño Negro, auspiciado por el programa Iniciativas Estudiantiles de la Vicerrectoría de Acción Social (VAS) de la Universidad de Costa Rica (UCR), entre el 2015 y el 2017.

\section{Introducción}

La motivación de este trabajo surge del adverso panorama que enfrentan las personas habitantes de la Zona Norte Norte de Costa Rica (ZNN). La cooptación del sector agrícola bajo un modelo industrial, para este caso piñero y naranjero, forma parte de los factores que inciden en la degradación sistemática de las condiciones laborales, económicas, sociales y ecológicas de la región.

Este trabajo tiene como objetivo analizar la evolución del aparato productivo y el expansionismo piñero y naranjero por medio de la identificación de los actores empresariales (elites) y las condiciones de las personas locales (empobrecidos) en la ZNN, a fin de comprender los comportamientos antagónicos a lo largo de la historia entre el modelo extractivista de los monocultivos y las condiciones ecosociales de las comunidades locales.

El sistema agrícola convencional/productivista, también conocido como modelo agrícola industrial, se caracteriza por preferir los monocultivos y la producción a gran escala, utilizar prácticas de producción intensivas recurriendo fuertemente al uso de capital, tecnología e insumos petroquímicos externos, y orientarse al mercado nacional y cada vez más al global gracias a la liberalización del comercio agrícola y las políticas de seguridad alimentaria basadas en el comercio internacional (Monsalve Suárez y Emanuelli, s.f., 5).

A manera de estructura, se aborda la catástrofe ecosocial que está enfrentando la humanidad, lo cual intensifica la privatización y la guerra por lo último que queda. Los siguientes apartados están dedicados a la forma en la que se configura ese saqueo y esa explotación, por medio de los monocultivos tanto piñeros y naranjeros, que genera millonarios ingresos económicos, pero a veces con incumplimientos laborales, salariales y ambientales. A manera de conclusión, se plantean líneas de investigación que pueden enriquecer la discusión de la compleja temática.

\section{Aspectos metodológicos ${ }^{1}$}

Se entiende por ZNN los cantones de Los Chiles, Guatuso y Upala, excepto San Carlos debido a que, tanto su conformación histórica como su configuración socioeconómica presentan importantes divergencias con respecto a los cantones supracitados. San Carlos fue fundado por Ley n. ${ }^{\circ} 17$, emitida el 25 
de setiembre de 1911, mientras que los cantones de la ZNN no surgieron hasta $1970 .^{2}$ Por lo tanto, en algunos casos se utilizará la delimitación de Región Huetar Norte (RHN) (que incluye San Carlos), en razón de que gran parte de las fuentes así lo muestran.

Se aplica la metodología relacional o "impura" de los derechos humanos que propone Joaquín Herrera Flores, ya que plantea establecer los derechos humanos como punto de partida; esto es, colocar los derechos humanos en el espacio donde nos movemos (acción), en la pluralidad (corporalidad) y en el tiempo (historia), lo que permite plantear métodos multi y transdisciplinarios, puesto que las distintas áreas de conocimiento siempre están "contaminadas" del contexto e hibridizadas entre sí (Herrera Flores 2008).

Además, se utiliza la metodología de prosopografía, que investiga las características de un grupo de individuos para hacer un estudio de sus vidas en colectivo y su influencia en las redes de poder (Ferrari, 2010). En este caso, el estudio se halla enfocado en la producción piñera y naranjera de la ZNN, y sus vínculos con instituciones estatales, casos de corrupción y ligámenes con otras compañías. También se llevó a cabo revisión de fuentes primarias y secundarias (tanto cualitativas como cuantitativas) acerca de la producción piñera y naranjera, muchas de ellas oficiales, con visitas de campo y trabajo de acción social en la comunidad de Caño Negro (El Sitio y Las Flores). Se realizaron unas 24 giras de campo entre el 2015 y el 2017.

La periodización abarca desde 1974, cuando León Araya (2015) afirma que la RHN comenzó a ser reconocida como tal, hasta el 2015, fecha a la que llegan muchos de los datos estudiados. Algunos datos a nivel nacional como el caso de la naranja se conocen desde 1961; por eso, han sido también incluidos. Mientras que los de la piña han sido tomados desde la década de los ochenta, cuando la actividad comenzó a ser más significativa.

\section{Despojo y colapso}

Al igual que con el "grano de oro', que fue parte del mito fundacional de "igualiticos", el impulso a los nuevos "frutos de oro" ha llevado también al enriquecimiento de unos pocos, en ocasiones por causa del plustrabajo, ${ }^{3}$ esclavitud y extrema pobreza de otros, porque según Herrera Flores (2008), el desarrollo neoliberal es antagónico a los derechos humanos, en tanto que su evolución depende de una estructura relacional de acumulación y despojo.

El culto triunfante de la mercancía alienta todos los egoís-

mos y justifica todas las mezquindades, y exalta el desprecio suicida de la vida y la renuncia a toda dignidad, al despecho de todas las gesticulaciones "ecológicas" y "éticas" del comercio (...) (Black, 2013, p. 53).
2. La Ley $\mathrm{N}^{\circ} 4541$ del $1^{\circ} \mathrm{de}$ abril de 1970 segregó del cantón de Grecia a los distritos de Upala, Guatuso y Los Chiles, con el objetivo de convertirlos en cantones.
3. Según Veltmeyer y Petras (2015), el plustrabajo es la parte de la jornada laboral en la que el trabajador produce para enriquecer al propietario de los medios de producción mientras que el trabajo es la parte de la jornada en la que el trabajador produce el equivalente a su salario. 
Es notorio el desplome socioeconómico desencadenado en parte por el contexto de la implementación de los Programas de Ajuste Estructural (Pae), como medida de algunos países latinoamericanos para recibir préstamos del Banco Mundial (BM) y el Fondo Monetario Internacional (FMI) que facilitaron librarse de la crisis de los setenta y también como medida de Estados Unidos para expandir su área de influencia ante su crisis de sobreoferta (ajustes espacio-temporales), que ha devenido en la instalación de corporaciones en los países ahora colonizados por dicha nación, generando lo que Harvey denomina acumulación por desposesión (Petras y Veltmeyer, 2002; Harvey, 2003; 2005).

El uso de tecnología avanzada, la implementación de un régimen regulatorio relacionado con el capital extractivo y la canalización de algunas rentas procedentes de los recursos hacia el bienestar social (reducción de la pobreza) no han cambiado la naturaleza inherentemente depredadora del capitalismo extractivo. Todo lo que este progreso y estos desarrollos han asegurado es un mayor nivel de explotación con su acompañante impacto destructivo sobre la sociedad y el medioambiente (Veltmeyer y Petras, 2015, p. 29).

Este capitalismo depredador también ha provocado la destrucción y el saqueo extremo de los recursos, algunos de los cuales son vitales para satisfacer el descontrolado consumismo y la acumulación capitalista. Según Saxe Fernández (2005), tal situación ha tomado dimensiones de colapso social (asesinatos, egoísmo, traición, suicidios, medios de des/información, esclavitud, pobreza, hambrunas...), y de colapso ecológico (sequías, inundaciones, colapso climático, sed, contaminación, destrucción y agotamiento de recursos...), que han sido parte del proceso destructivo-acumulativo a lo largo de la historia de la humanidad (Leakey y Lewin, 1998).

Definitivamente, en las zonas rurales y alejadas el sistema (capitalista e imperialista) logra con más facilidad tener acceso a los recursos y someter a las poblaciones, debido a que estas cuentan con información mínima o nula sobre las formas oficiales de defenderse, además de que han sido zonas históricamente marginadas, y con personas de por vida engañadas por la supuesta llegada del "desarrollo" gracias a fuentes de empleo que les permita por fin salir de las condiciones que las mismas corporaciones han creado. 
Breve repaso de la constitución histórica de la Región Huetar Norte y su inclusión al proyecto nacional costarricense

León Araya (2015) aborda la poca intervención del Estado en esta zona desordenadamente colonizada, con un incipiente desarrollo ganadero, cañero y cafetalero, pero con casi nula educación y poca intervención estatal. Esta última poco a poco se fue incrementado en cuanto también aumentó el interés colonizador, el cual tuvo poco éxito antes de la década de 1960 (Valverde, 2011).

Según Solórzano (2004), migrar hacia nuevos frentes de colonización donde la tierra era abundante y barata, pudo ser percibido no solo como un mecanismo de movilidad social, sino también como la posibilidad de convertirse en propietarios de fincas de mayor tamaño, sobre todo si se toma en cuenta que los precios de las tierras iban en aumento en las zonas de origen de estos migrantes.

Con respecto a los factores de atracción, uno de los principales fue la importancia geopolítica de ejercer la soberanía a lo largo del territorio nacional. La maximización de utilidades que conllevó el modelo agroexportador adoptó legislación agraria que promovió y facilitó la formalización de la posesión de tierras baldías, siempre que se demostrara su aprovechamiento adecuado (León Araya 2015).

Si bien es cierto que durante el siglo $X X$ hubo acontecimientos que mejoraron la conexión y el acceso entre la Zona Norte y el Valle Central -fundación de cantones, llegada de instituciones públicas, construcción de caminos, etc.-, es importante destacar que la dinámica transfronteriza es una constante que ha perdurado y que marca a la región en diversos aspectos tales como: la constitución -o la no constitución- de una identidad regional y nacional, las condiciones laborales, el planteamiento estatal y las prácticas culturales, por ejemplo.

Lo anterior ha sido evidente sobre todo durante la dinastía de los Somoza y la revolución Sandinista y la Contra desde Costa Rica, apoyada por Estados Unidos (Fonseca, 2013; Almeida, 2016). Dicho conflicto impulsó el desplazamiento de nicaragüenses de poblados principalmente del departamento de río San Juan hacia el norte costarricense; muchos de ellos tuvieron que llegar a realizar trabajos subordinados a los terratenientes ya establecidos en la zona (Cortés Ramos, 2003), o en los incipientes desarrollos monocultivistas que estaban empezando a gestarse (Fallas Baldí, 1994).

\section{Extractivismo y ajustes estructurales en la Región Huetar Norte}

Con la implementación del modelo neoliberal a partir de la década de los ochenta, la reducción del tamaño del Estado y la desnacionalización de algunos recursos, numerosas compañías multinacionales y multimillonarias se instalaron en el país con las facilidades y los beneficios que el Estado les ha brindado hasta la actualidad (Llaguno Thomas, Cerdas Vega y Aguilar Sánchez, 2014; Veltmeyer y Petras, 2015; Silvetti y Cáceres, 2015). 
Tal es el caso de los Certificados de Abono Tributario (Cat), que fueron incentivos dados a productores para que exportaran sus productos en los setenta (La República, 1976); no obstante, dichos beneficios se dirigieron entre 1993 y 1996 a compañías como la piñera Pineapple Development Company (Pindeco), que fue la que más recibió incentivos (unos $\$ 3243$ millones). Asimismo, la liberación de impuestos de las empresas exportadoras piñeras ocurrió en el marco la Iniciativa de la Cuenca del Caribe (ICC), que las liberó de toda responsabilidad tributaria por consumir productos e insumos que se encuentran en zona franca (Aravena Bergen, 2005).

Entre 1987 y 1997 se promovió una economía muy diversificada e intensiva de actividades tradicionales y no tradicionales en la RHN, con mercados internos (leche, tubérculos, caña de azúcar, granos básicos, etc.), y mercados externos (cítricos, palmito, ornamentales, jengibre, madera, naranjas, raíces y tubérculos). El modelo de apertura comercial, si bien aportó a la expansión de la productividad, como lo menciona Zevallos (2013), ha afectado negativamente a las pequeñas economías.

Según Procomer (2016), 10.8\% de las exportaciones totales del país proviene de la RHN. El monto exportado en el 2016 fue de US\$1 068 millones, de los cuales $65.1 \%$ fue piña y $12.1 \%$ jugos y concentrados de fruta. Igualmente, las tres principales empresas exportadoras de la región son: 1) Corporación de Desarrollo Agrícola del Monte S.A., 2) Ticofrut S.A., 3) Diversificados de Costa Rica (Dicori), y también se encuentran Upala Agrícola y Exportaciones Norteñas, en las posiciones 5 y 7, respectivamente (Procomer 2016). Ambas empresas serán abordadas posteriormente en este trabajo.

Varias fuentes sobre las condiciones productivas de la RHN (Quijandría, Berrocal y Pratt, 1997; Barrientos y Chaves, 2008; Guevara, Arce y Guevara, 2017, entre otras) sostienen que las actividades se han ido diversificando hacia el turismo, el desarrollo hidroeléctrico y la expansión piñera como actividad más llamativa, llegando a ser una de las zonas más productivas del país (Estado de la Nación, 2016). Sin embargo, estos estudios se quedan cortos en el reconocimiento de las -verdaderas- condiciones sociales de la región. Por otro lado, los estudios -por cierto abundantes- que critican estos modelos de desarrollo (como Humbert y Braßel, 2016; Carazo, 2016), aunque revelan datos fundamentales, no van mucho más allá de la problematización de la situación y la búsqueda de mejoras laborales.

En los últimos años, la situación piñera en Costa Rica, y en algunos casos la naranjera, ha tomado tanta relevancia que decenas de organizaciones públicas y privadas han hecho críticas contra las catástrofes socioambientales y contra el uso intensivo de agrotóxicos. El fenómeno es un común denominador en la región latinoamericana, infestada de conflictos socioambientales ante los invasores y depredadores proyectos de "desarrollo" (ver el Environmental Justice Atlas), convirtiendo a América Latina en la región con la distribución más desigual de la tierra en el mundo (Guereña, 2016). 


\section{La consolidación del cultivo de piña}

La piña es un cultivo que ha tomado relevancia en el nivel de exportaciones reportadas en la balanza de pagos de Costa Rica. Esta fruta se ha producido en el país desde el tiempo de la colonia, principalmente para el consumo interno. Antes de la década de los setenta del siglo XX, las exportaciones de piña no tenían gran relevancia para el país. Empero, existen antecedentes de que particulares hacían pruebas de exportaciones con grandes ganancias. Para mediados del siglo XX, el cultivo de piña para el mercado interno ya formaba parte de la actividad económica de algunos productores.

Un anuncio publicado en el Diario de Costa Rica en 1935 demuestra que:

El consumo interno de la piña ha aumentado y también el externo, ya que comienzan los particulares a exportar pequeñas partidas. Pero el país tiene muchas tierras donde sembrar piñales. En la región de Puntarenas se han hecho ensayos con muy buenos resultados. Un solo finquero sembró varias hectáreas y está en condiciones de suministrar veinte mil piñas, pero no tiene comprador (Diario de Costa Rica, 1935).

Su desarrollo agroindustrial tiene precedentes en el siglo $X X$, específicamente a finales de la década de los setenta cuando la transnacional Pindeco inició operaciones en la Zona Sur del país (Quijandría, Berrocal y Pratt, 1997). Pindeco, con sus condiciones comerciales de "satellite farming", impulsó el monocultivo extensivo, en el que los productores ponían la tierra y la mano de obra, mientras que la transnacional aportaba la tecnología y garantizaba la compra del producto (Quijandría, Berrocal y Pratt, 1997).

Adicionalmente, la creación de organismos como el Programa Nacional de la Piña, la Coalición Costarricense de Iniciativas de Desarrollo (Cinde), el Centro para la Promoción de las Exportaciones y las Inversiones (Cenpro), exenciones como el Contrato de Exportación y el de Zona Franca, los Cat y el beneficio de Zona Franca (sin requerimientos ambientales) han sido los factores de la expansión piñera descontrolada en el país (Quijandría, Berrocal y Pratt, 1997). 


\section{Gráfico 1. Evolución de las exportaciones de piña en millones de dólares y toneladas (1980-2015)}

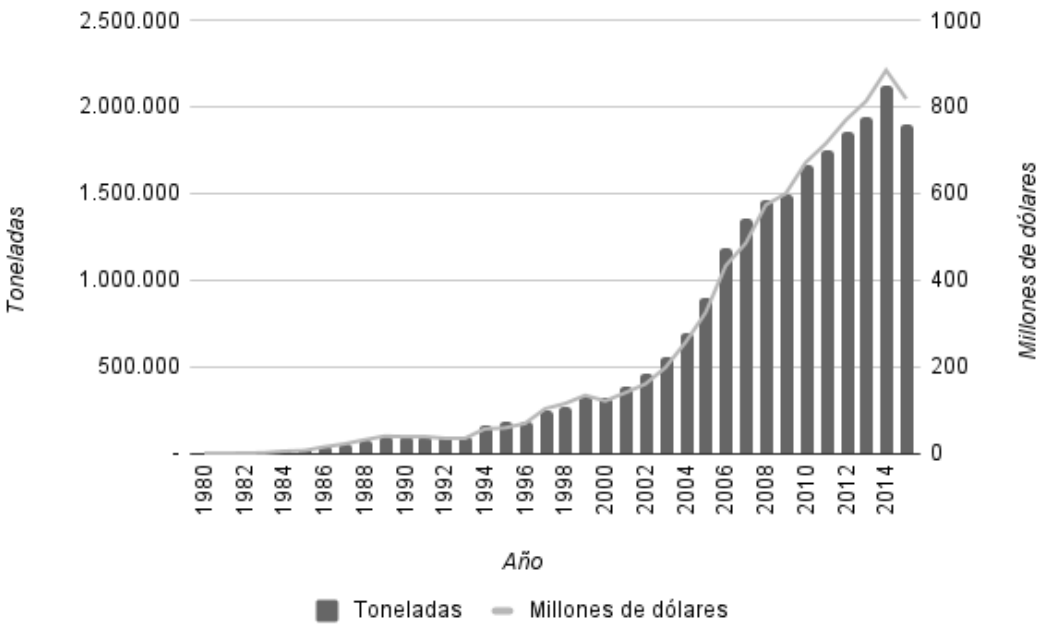

Elaboración propia con datos de Procomer, Quijandría, Berrocal y Pratt (1997), y Mora Alfaro (1994).

El crecimiento exponencial de las exportaciones de piña se evidencia en el gráfico 1. Las cifras alcanzan casi US $\$ 900$ millones para el 2014. Según la Cámara Nacional de Productores y Exportadores de Piña (Canapep), las exportaciones al 2015 tienen destino hacia: 53\% América del Norte, 44\% Unión Europea, 2\% resto de Europa y 1\% a otros destinos. Estos datos deben analizarse con cuidado, debido a la nula supervisión estatal. Para comprender mejor los crecimientos respectivos por periodo, se utiliza la Tasa de Crecimiento Anual Compuesta (TCAC), la cual arroja los siguientes resultados (tabla 1):

Tabla 1. Tasa de Crecimiento Anual Compuesta para la producción de piña en la Región Huetar Norte (1980-2015)

\begin{tabular}{cc}
\hline Años & TCAC por periodo \\
\hline $1980-1989$ & $78.8 \%$ \\
$1989-2000$ & $11.2 \%$ \\
$2000-2015$ & $12.6 \%$ \\
$1980-2015$ & $26.3 \%$ \\
\hline
\end{tabular}

Elaboración propia con datos de Procomer, Incae y Mora Alfaro (1994).

Desde 1980 hasta el 2015, el crecimiento en exportaciones de piña ha sido superior a $26 \%$ anual, lo cual es mucho más de lo que ha crecido el Producto Interno Bruto real (PIB) de Costa Rica en ese periodo (4.0\%) (Secmca, 2017). El desarrollo acelerado de la piña no es casualidad. Por ejemplo, el sistema bancario costarricense ha impulsado la actividad mediante sus políticas de crédito. El Banco Nacional de Costa Rica (BNCR) otorgó créditos en 1982 por US\$34 906, y para 1984 un monto de US\$212 273 a la actividad pi- 
ñera, lo que significó un aumento de más de $500 \%$ en tan solo dos años para un solo sector (Quijandría, Berrocal y Pratt, 1997).

\section{Gráfico 2. Distribución de las hectáreas dedicadas al cultivo de piña en Costa Rica (2015)}

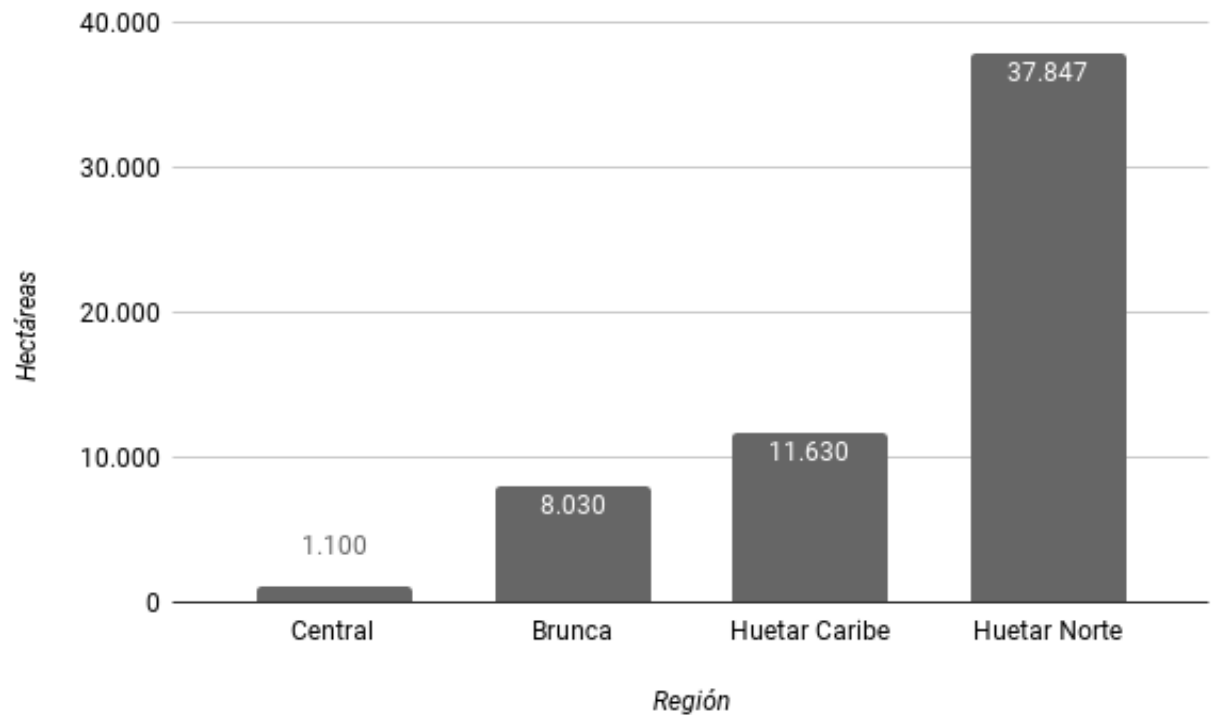

Elaboración propia con datos de Sasa (2017).

Los recientes datos proporcionados por el Monitoreo de Cambio de Uso de Paisajes Productivos (Mocupp) (Sasa, 2017), revelan una cantidad muy superior (58 607 hectáreas) que la reportada por Canapep (43000 hectáreas) en el país (Guevara, Arce y Guevara, 2017). La Canapep ha asegurado que se debe a que no todos los productores están afiliados a la cámara; sin embargo, fuentes como Guevara, Arce y Guevara (2017), siguen usando los datos de Canapep como totales a nivel nacional. El valioso aporte de Sasa (2017) no solo demuestra la expansión ilegal de la producción de piña, sino también la inoperancia de las instituciones que ni siquiera conocen cuántas hectáreas de piña hay en el país, con una subestimación de 15607 hectáreas.

La apertura de los mercados piñeros en China durante la administración Solís Rivera (2014-2018) no solo va dirigida hacia el incremento de la producción piñera, sino que también ha generado grandes debates en Costa Rica sobre el rumbo que esta actividad debe tomar, la cual, sin muchos requerimientos ambientales, ha logrado extenderse ilegalmente 5568 hectáreas, incluso talando bosques (3 192 en la RHN) (Sasa, 2017). ${ }^{4}$ Mientras que al sur del país, ha llegado muy cerca del sitio arqueológico de las esferas de piedra en Sierpe-Osa, declarado Patrimonio Mundial de la Humanidad. La invasión
4. Los diversos estudios en la Estación Biológica La Selva (por tomar un caso), han identificado más de 2000 especies de plantas (desde musgos hasta árboles) (ver Flórula Digital de La Selva 2017), mientras que en las plantaciones piñeras, esa diversidad vegetal llega a apenas unas 58 especies (únicamente hierbas y arbustos arvenses), las cuales constantemente son controladas con agrotóxicos (Brenes Prendas y Agüero Alvarado, 2007). 
ocurre contra la naturaleza y también contra las personas, y es recurrente en otros monocultivos, como se detallará con el caso de la naranja.

\section{Las élites piñeras de la Región Huetar Norte}

La agroindustria de la piña, a diferencia de la Zona Sur, está distribuida en varias empresas. Para este caso, se analizan tres empresas agroexportadoras, que representan aproximadamente $40 \%$ del total de hectáreas cultivadas en la RHN.

Quizás convenga comenzar con Finca Once, también conocida como Natura Farms LWO. Es una empresa ubicada en Los Chiles y está representada por Oscar Arias Moreira. Tiene una extensión de 1064 hectáreas, de las cuales $35 \%$ corresponde a zonas de protección de quebradas, y cuenta con 314 trabajadores, de quienes $99 \%$ pertenece a la Asociación Solidarista Asefio (Chavarría Hernández, 2012b).

Un artículo del Semanario Universidad (Chavarría Hernández 2012b) revela los vínculos de Arias Moreira, exprofesor de la Universidad de Costa Rica (UCR), con la petrolera Mallon Oil, la cual desde el 2000 ha intentado obtener permisos para la exploración y explotación petrolera, precisamente en los terrenos protegidos de Finca Once. Oscar Arias Moreira es esposo de Elizabeth Rosabal Oller, prima de Pedro Oller Taylor, representante de Mallon Oil en Costa Rica.

Se tiene poca información sobre esta finca. Entre lo que se conoce, está que Arias Moreira posee muchas de las empresas piñeras y de naranjas de la región, entre ellas Cítricos de Guanacaste, Finca Once, Hacienda R y R, Del Oro, Bana Internacional Aéreo, y Persona de Costa Rica, ubicadas en Upala, Los Chiles, San Carlos, Guatuso (Alajuela), y en La Cruz (Guanacaste) (Chavarría Hernández, 2012b).

Otra empresa es Exportaciones Norteñas, propiedad de Rodrigo García Brenes y Michael Boasson, también conocida como Santa Fe y ubicada en Los Chiles. Según fuentes de la prensa, cuenta con una extensión de 3500 hectáreas (Socialismo Hoy, 2016). Noticias periodísticas muestran prácticamente solo denuncias contra esta compañía: explotación laboral, bajos salarios y contaminación (Socialismo Hoy, 2017a; 2017b). Sin embargo, las versiones de las compañías pocas veces son mostradas, lo cual dificulta generar un mejor mapeo de actores.

Asimismo, García Brenes es propietario de Piña de Exportación Mundial S.A., la cual cuenta con una extensión de 634 hectáreas de cultivo. Este proyecto recibió la aprobación de viabilidad ambiental por parte de Setena en setiembre del 2016, lo cual evidencia la continua expansión piñera y las relativas facilidades para obtener aprobación (Setena, 2016).

Un artículo promocional publicado en La República (2016), sostiene que Upala Agrícola cuenta con más de 2400 hectáreas de este cultivo. Es presidida por Alfredo Volio Pérez, actual vicepresidente de Canapep y exministro de Agricultura en la segunda administración de Óscar Arias Sánchez (2006- 
2010), quien renunció en el 2007 para asumir la campaña del Sí al TLC (Rojas, 2007). Fue presidente de la Junta Directiva del BNCR durante la administración de José María Figueres Olsen (1994-1998) y en el 2010 fue elegido nuevamente para ocupar ese cargo (Delgado Montoya 2010). Además, esta empresa ha sido señalada por la prensa por adeudar a la Caja Costarricense de Seguro Social (CCSS) más de $\$ 73$ millones (Chavarría Hernández 2012a).

El padre de Volio Pérez, Alfredo Volio Escalante, fue exdirectivo del BNCR entre 1970 y 1978, y recientemente estuvo involucrado en las estrategias de evasión y elusión de impuestos de los Panama Papers (Madrigal, 2016; Rojas, 2016). La familia Volio aparece involucrada prácticamente en todos los periodos de la historia de Costa Rica, caracterizada por pertenecer a las elites político-económicas del país.

El sector piñero también está ligado con la Cámara de Comercio Exterior de Costa Rica (Cadexco), por ejemplo, por medio de Geovanni Villalobos Venegas quien es subtesorero de esta y tesorero de Canapep (Cadexco, 2017; Canapep, 2017a). Además, el Incae, la Promotora de Comercio Exterior de Costa Rica (Procomer) y Bac San José se han centrado en legitimar la actividad piñera en el país, gracias a estudios de impacto, lobby político y asesorías en el tipo de cambio (Corrales Brenes, 2017; Chávez Trigueros, 2017; Canapep, 2017b).

Es decir, la pequeña elite que la producción piñera conforma en la región está estrechamente ligada a las principales potencias agroindustriales y económicas, y a su vez, a cargos públicos en el país. Para el caso de la naranja, que se abordará en otro apartado, también están presentes las relaciones de poder y la influencia en los aparatos estatales.

\section{El jugoso negocio naranjero}

Existe bastante menos información para la naranja con respecto a la piña. Las fuentes sobre la naranja se basan en el ámbito productivo y colocan la producción naranjera como un cultivo apropiado por tener hábito de árbol, aunque sin tratar las problemáticas en torno al uso de agrotóxicos y las situaciones laborales (Quirós Arias, 2001; IICA, 2004). La situación de las personas trabajadoras en las plantaciones naranjeras comenzó a hacerse más visible a partir las denuncias que fueron divulgadas por algunos medios de comunicación (sobre todo, por Socialismo Hoy).

El desarrollo de los cítricos se enmarcó a partir de los años sesenta del siglo $\mathrm{XX}$, con financiamiento del proyecto denominado Corena 032, que pretendía darle cobertura al suelo con especies frutales. Pero el éxito de este proyecto no se reflejó hasta 1985, cuando los precios del café cayeron, se desestimuló la producción en América Central, y se dio el advenimiento de la Comunidad Económica Europea (Cee). Al mismo tiempo, se desarrollaban plantas agroindustriales procesadoras de jugo concentrado (JCC) de naranja en la Zona Norte, que estaba teniendo éxito económico a nivel internacional (Quirós Arias, 2001). 


\section{Gráfico 3. Área cultivada de naranjas en Costa Rica (1961-2013)}

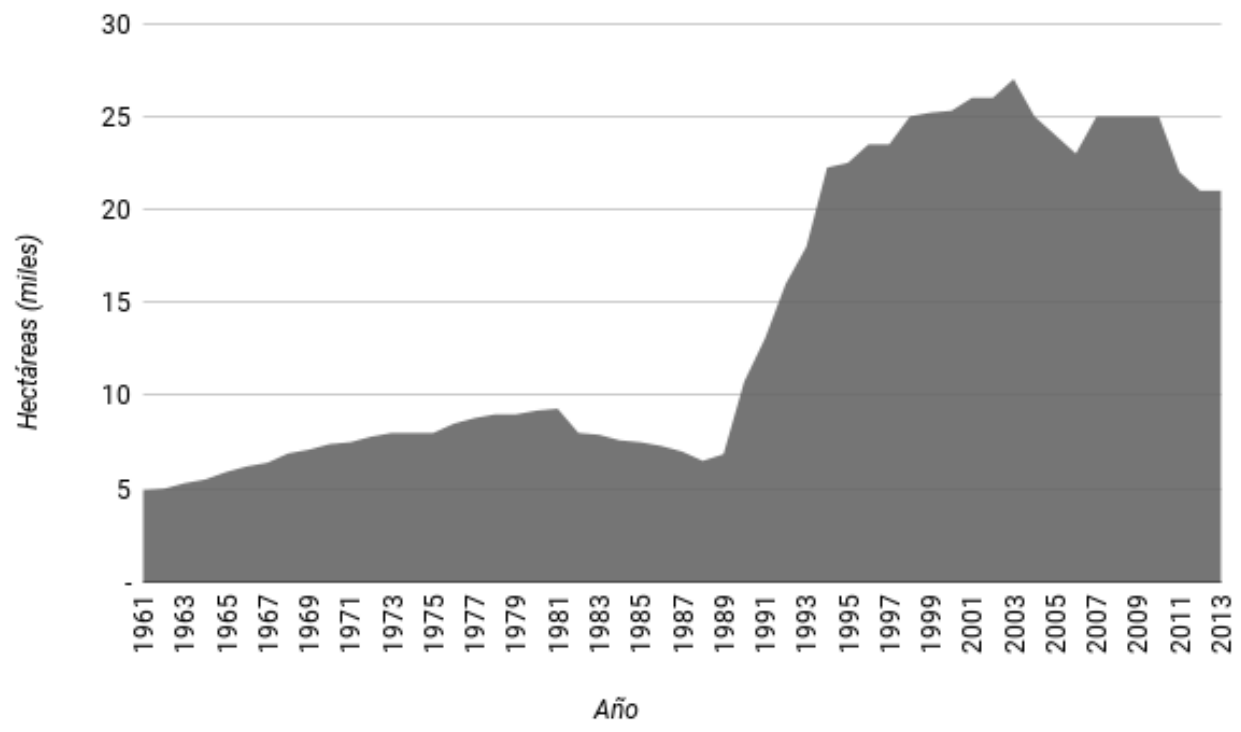

Elaboración propia con datos de Fao (2017).

A partir de 1985, las políticas neoliberales y sus ajustes estructurales promovieron la expansión monocultivista, por medio de programas especializados para las principales actividades agropecuarias del país. Esto llevó a la creación de un programa nacional de naranja y cítricos, dirigido a todas aquellas regiones con potencial agroecológico. Desde entonces, los cítricos se han impulsado en las regiones: Central Sur, Central Occidental, Central Oriental, Brunca y Norte (Jiménez Acuña, 2012).

Como se detalla en el gráfico 4 , hubo un crecimiento de la producción de naranja a partir de los ochenta. Se debió a que por esos años estaba en aumento el consumo de jugo del cítrico por la divulgación de sus propiedades beneficiosas para la salud (Quirós Arias, 2001; Jiménez Acuña, 2012).

En aquel marco de demanda, llegaron compañías como la fabricadora de jugo Del Oro (de capital inglés) y Ticofrut, esta última fundada en 1988 para producir jugos cítricos; tales empresas han acaparado cerca de $70 \%$ de la producción nacional (IICA, 2004; González, 2014), además de pequeños y medianos productores motivados en esos años a sustituir sus cultivos tradicionales por la siembra de cítricos, al tiempo que desplazaron producciones de subsistencia o comercio local (Faure y Samper, 2004; Baltodano y Rojas, 2005). 


\section{Gráfico 4. Producción naranjera en Costa Rica (1961-2013)}

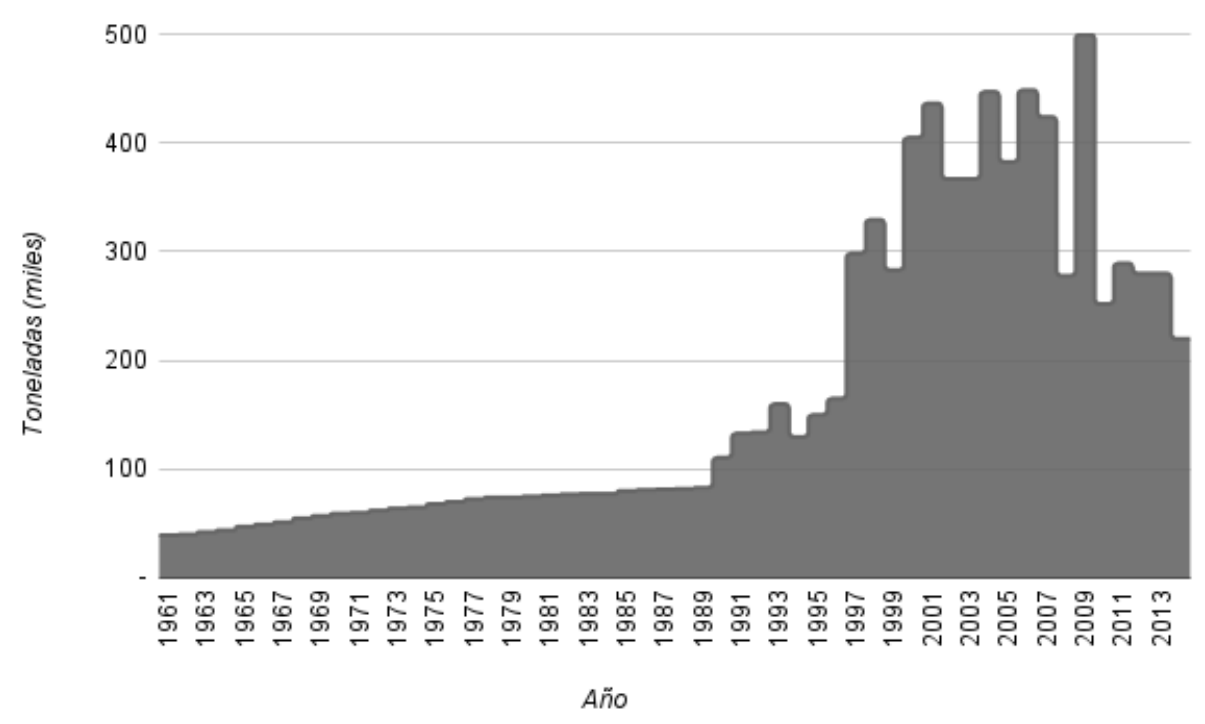

Elaboración propia con datos de Fao (2017).

La sustitución conllevó al drenaje de humedales, la tala y la contaminación de ríos (Gutiérrez y Siles, 2009). Con los terrenos listos para la siembra y cosecha expansiva de naranja en monocultivo, se construyó la planta procesadora de Ticofrut en la comunidad de La Palmera de Aguas Zarcas (no estudiado en este trabajo), provocando problemas de contaminación (Baltodano, 2002; Baltodano y Rojas, 2005).

Gráfico 5. Exportación de concentrado, jugo preparado y naranjas en Costa Rica (1983-2013)

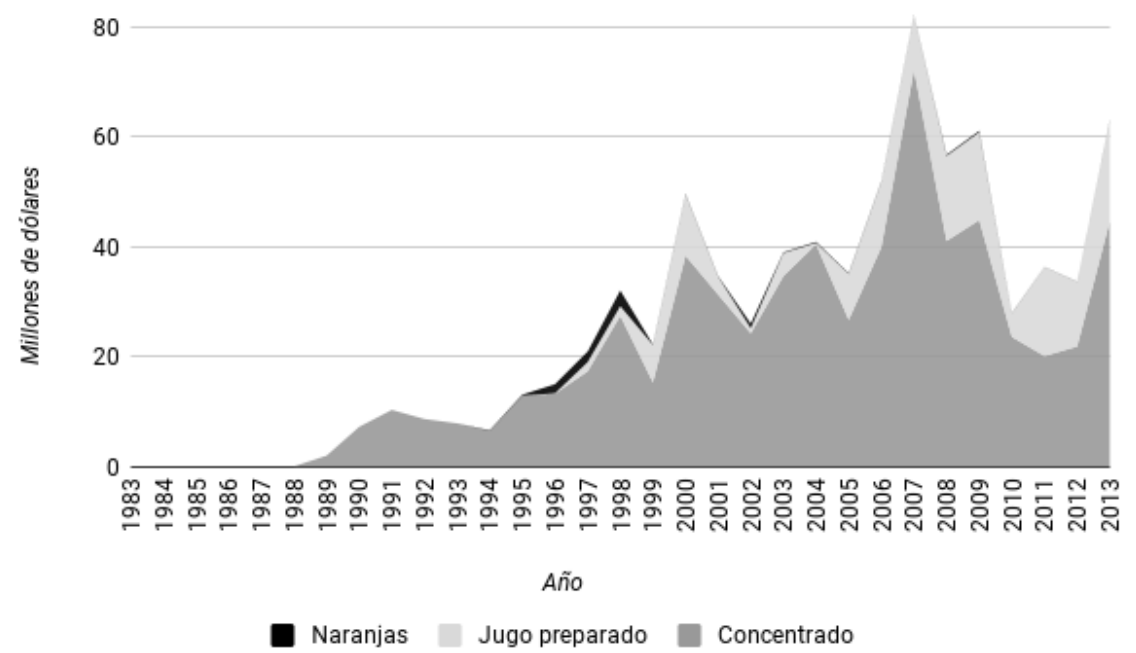

Elaboración propia con datos de Fao (2017). 
5. Tope fue una de las personas con mayor experiencia en el área de los cítricos. Fue contratado por Ticofrut cuando aún era propiedad de su fundador, Carlos Odio Soto.

6. Esta empresa también se dedica a la venta de productos como huevos, aves, especias, hierbas, café y té.

7. Su hermano, Alfredo Pellas Chamorro, quien murió en el 2015, fue un importante agente impulsor de la privatización en Nicaragua. Fue conocido por ser el director de The Nicaragua Sugar Estates Limited y de la Compañía Licorera de Nicaragua, fabricante del conocido ron Flor de Caña.

8. Grupo Pellas, con más de 100 años de recorrido, cuenta con negocios en el sector financiero, seguros, agroindustrial, informático, energético, distribución de vehículos, producción y comercialización de cervezas y licores.
Más allá de la oscilación, es un mercado dominado por Ticofrut (a pesar de problemas con plagas). La ZNN, en su tendencia monocultivista, aumentó las exportaciones a mediados de los 90 , después de implementar el cultivo naranjero a mediados de los 80 (Ver gráfico 5).

También del gráfico 5 se desprende que la empresa ha logrado abarcar 93\% de la producción de naranja del país, siendo su destino la comercialización como fruta fresca y el procesamiento de jugo congelado para la exportación a países industrializados como Estados Unidos, Canadá, Alemania, Holanda, entre otros (Earth, 2004).

\section{La élite naranjera en la Región Huetar Norte}

En primer lugar, para la conformación de la elite naranjera, comenzaremos con Antonio Lacayo Oyanguren (1947-2015), quien fue un nicaragüense que ocupó el cargo de ejecutivo del Grupo Pellas (2000-2015) y fue gerente de Ticofrut en el 2014. Fue también ministro de la Presidencia nicaragüense durante la administración de su suegra, Violeta Chamorro Barrios (1990-1997). Se caracterizó por ser uno de los impulsores de las privatizaciones de los bienes estatales en Nicaragua y los ajustes al modelo del FMI. Además, en 1992, estuvo involucrado en el Caso Lacayo (corrupción por desvío de fondos).

En el 2015, Lacayo Oyanguren murió en un accidente aéreo, acompañado de Phillip Wendell Tope,$^{5}$ gerente desde los noventa de Tampa Juice Service, dueña de la marca comercial de Ticofrut. Tampa es una empresa de origen estadounidense (específicamente, Florida) comercializadora de jugos procesados, ${ }^{6}$ que fue fundada a inicios de los noventa del siglo XX (Bloomberg, 2017).

En el accidente también murió James Scott Horrisberger, presidente de compras de Coca Cola Company, principal comprador de naranjas de Ticofrut, y experto en los negocios cítricos. Había estado en la industria durante tres décadas con Peace River Citrus Products (competencia de Tampa) y fue miembro de la Comisión de Cítricos de Florida (Morelli, 2015). El mortal viaje iba rumbo a una reunión con Carlos Pellas Chamorro, ${ }^{7}$ conocido como "El Rey del Azúcar", y presidente del poderoso Grupo Pellas. ${ }^{8}$

Un año antes, el nicaragüense Grupo Pellas, en conjunto con el panameño Grupo Motta, de Stanley Motta, conocido por ser el hombre más rico de Centroamérica y enriquecido especialmente con los "duty free" en los aeropuertos latinoamericanos, habían adquirido $60 \%$ de las acciones de Rivara Holding, la sociedad que controlaba Ticofrut (Central America Data, 2014). La adquisición por parte de Pellas y Motta marcó un punto importante, ya que se intensificaron las denuncias sobre injusticias contra las personas trabajadoras.

Después de la muerte de Lacayo Oyanguren, el puesto gerencial fue asumido por el costarricense Carlos Odio Soto, dueño de $40 \%$ de Ticofrut, quien laboró en el Ministerio de Industrias de Costa Rica en 1965 y fue jefe de depar- 
tamento en 1966. En 1988, fundó Ticofrut y fue su dueño total hasta el 2014, cuando pasó a manos de Pellas y Motta. Esta alianza se forjó desde 1991, cuando Pellas y Motta se involucraron en la distribución de bienes y servicios tecnológicos de International Business Machines (IMB). El grupo Pellas es también el responsable del complejo turístico en Guanacaste, que ha dejado sin agua a cientos de personas de la zona (Rosales y Ávila 2014).

Ticofrut no se escapa del escándalo de los Panama Papers. La empresa aparece mencionada entre las que intentaron evadir impuestos mediante su inversión en paraísos fiscales. Alberto Raven Odio, presidente por tercera vez del Banco de Costa Rica (BCR), secretario de Ticofrut, y uno de los apoderados del equipo de fútbol costarricense Deportivo Saprissa, aparece vinculado por medio del bufete Zürcher, Odio \& Raven en al menos 62 sociedades, entre ellas la empresa naranjera vinculada a los paraísos fiscales (Asamblea Legislativa, 2017).

Cabe mencionar que en Zürcher, Odio \& Raven se encuentra, entre otros empresarios, Edgar Zürcher Guardián, quien es presidente del Banco Promérica e impulsor de la llegada de los almacenes Pricesmart y de las zapaterías Payless. Raven Odio vinculado a los paraísos fiscales en Bahamas, fue presidente del BNCR (1997-1998) y vicepresidente del Instituto Nacional de Seguros (INS) (2006-2010).

Database asegura que Ticofrut es un engranaje de al menos siete sociedades anónimas domiciliadas en Panamá, que el bufete Zürcher, Odio \& Raven, como enlace del bufete panameño Mossack Fonseca (del que se filtraron los Panama Papers), ayudó a registrar a Rivara Holdings, Coberton Holdings, Morumbí, Combuhy, Sedgwick Company, Serena Management y TicoSource (Fernández Morera y Jiménez Rueda, 2016). Por otro lado, el actual apoderado generalísimo de Ticofrut, Carl Edward Odio Trejos, realizó donaciones al Partido Liberación Nacional (PLN) por montos de $\$ 10800000$ y $\$ 7500000$ para las campañas del 2014 y del 2006, respectivamente (TSE, 2010; 2014).

\section{¿Naranja o piña?}

A pesar de ser dos cultivos muy diferentes, presentan muchos aspectos en común, generalmente negativos. La naranja es una especie arbórea, lo cual lleva a que tanto los estudios del Incae como de la Earth la muestren como una buena alternativa agrícola; mientras que la piña sí ha sido mucho más estudiada y criticada. Sin embargo, los estudios del lado desarrollista intentan convencer sobre los beneficios, en tanto los estudios críticos carecen de planteamientos alternativos, y más integrales que las desgastantes -pero fundamentales- denuncias burocráticas.

El primer aspecto común entre ambos cultivos recae en la inminente contaminación y destrucción para intensificar la productividad. Tal es el caso de las contaminaciones con agrotóxicos sobre el humedal Caño Negro, a pesar de estar protegido por el Refugio Nacional de Vida Silvestre Caño Negro, y que 
sea declarado sitio Ramsar (Acevedo y Zamora, 2011), el cual recibe toda la sedimentación y demás materia que es arrastrada hacia las lagunas (Samper, 2005; Boeglin, 2015; Montiel Segura, 2015). Estudios relacionados con temáticas biológicas no profundizan sobre la problemática socioambiental de los monocultivos y los agrotóxicos (Acevedo y Zamora, 2011).

Las prácticas de aplicación de agrotóxicos en los monocultivos son una de las causas que generan problemas ecosistémicos graves, como la muerte de peces o la contaminación de esos sitios (véase los hallazgos de Estado de la Nación, 2016). Cabe recordar que algunas personas locales en la ZNN poseen hábitos alimentarios en los cuales es frecuente el consumo pescado, lo cual genera una cadena tóxica que termina siendo mortal o al menos de malestar y sufrimiento.

El segundo aspecto común es la precarización de la población. La ZNN es una de las más empobrecidas y con más desigualdad económica en el país, por lo que alcanza los últimos lugares en el índice de Desarrollo Humano Cantonal (IDHc).

Tabla 2. Posición de Los Chiles, Guatuso y Upala en el Índice de Desarrollo Humano Cantonal (IDHc) (2010-2014)

\begin{tabular}{cccc}
\hline Año & Upala & Los Chiles & Guatuso \\
\hline $\mathbf{2 0 1 0}$ & 71 & 81 & 73 \\
$\mathbf{2 0 1 1}$ & 73 & 79 & 77 \\
$\mathbf{2 0 1 2}$ & 69 & 79 & 77 \\
$\mathbf{2 0 1 3}$ & 73 & 80 & 71 \\
$\mathbf{2 0 1 4}$ & 78 & 81 & 74 \\
\hline
\end{tabular}

Fuente: Atlas de Desarrollo Humano Cantonal (PNUD, 2017).

A pesar de alcanzar las mayores exportaciones en los últimos años, tanto Upala, Los Chiles y Guatuso han estado ocupando los últimos lugares (de los 82 cantones) en el IDHc. Los ingresos económicos de los peones agrícolas, ganaderos, campesinos sin tierra y pequeños agricultores se han venido deteriorando en los últimos años principalmente por las condiciones de producción y comercialización predominantes. Otra situación que impide el mejoramiento de las condiciones de vida de los agricultores de la zona ocurre justamente por las piñeras, que muchas veces les niegan a los pequeños productores la compra de las cosechas, lo que hace que ellos las pierdan.

Artículos como el de Chávez Trigueros (2016) muestran datos del IDH como un aspecto positivo: asegura que algunos años el IDH ha mejorado, lo cual tiende a la confusión en tanto solo se muestran datos deL 2004 y del 2014, sin considerar la oscilación entre esos años. Además, el aumento en el IDH ha sido mínimo, y en comparación con los demás cantones no ha significado mejoras, ya que los de la ZNN se encuentran en los últimos lugares del IDHc, como ya se menciónó. Si bien no puede atribuirse totalmente el rezago so- 
cioeconómico a este modelo económico -aunque sí en gran medida, mucho menos puede considerarse el modelo agroexportador piñero y naranjero como exitoso para las poblaciones locales, como lo asegura el artículo de Chávez Trigueros (2016).

Según la información divulgada en la prensa, los trabajadores no reciben muchas veces ni siquiera el salario mínimo establecido por ley. Cuando lo reciben por contratación formal, no es más que $\$ 20$ mil por encima del mínimo (Guevara, Arce y Guevara 2017). Empero, muchas veces ese monto no es suficiente para cubrir los gastos familiares o de los males sufridos por la esclavitud y el riego de agrotóxicos.

Como tercer aspecto podemos citar las condiciones laborales, las cuales desde los años 80 no han cambiado, a pesar de que existe una serie de leyes que respaldan a los trabajadores (Dubois, Mora, Parrado y Mora, 2016). Debido a la cercanía de la frontera, muchos de los trabajadores son nicaragüenses, algunos nacionalizados; mientras que otros tiene una condición migratorio irregular hace muchos años en Costa Rica y otros viajan diariamente cruzando la frontera. Se calcula que unas 12502 personas laboran en la industria piñera en la RHN (Humbert y Braßel, 2016), mientras que en la naranjera unas 4 000, y según la prensa, en su mayoría en malas condiciones (Socialismo Hoy, 2015).

Para el caso naranjero, una saca (es decir; 12 sacos convencionales) se paga a $\$ 3500$. En los últimos años, antes de cada zafra, se han llevado a cabo manifestaciones debido a las pretensiones de Ticofrut de pagar menos de $\$ 3000$. El salario no se cancela en efectivo, sino que se realiza por medio de una ficha que debe ser canjeada en negocios específicos. Si el trabajador desea obtener el dinero en efectivo, se le cobra una comisión de unos $\$ 300$. Además, debe habitar en un tipo de barraca, por las que paga unos $\$ 3000$. "(...) Solo a los chapulinistas les están pagando seguro ahí en esa naranjera, y a los que cortan no les pagan nada de seguro (social)". 9

El no pago de derechos laborales es denunciado en la prensa como una situación muy común, debido a que estas empresas se aprovechan de las necesidades socioeconómicas de las personas locales, y en algunas ocasiones del estatus migratorio, y la poca educación que poseen (véase el gráfico 6), en razón de las complicaciones para obtener permisos de residencia (de Jaude, 2005). Generalmente, les amenazan asegurando que si denuncian alguna de las injusticias vividas, van a ser despedidas o van a sufrir consecuencias más severas (Carazo 2016).

La población se desempeña principalmente en la agricultura o como jornaleros; otra pequeña parte labora en seguridad o construcción en zonas aledañas. Muchas de estas personas que logran conseguir trabajo deben desplazarse a zonas como Ciudad Quesada, Upala, Guanacaste e incluso Limón para poder traer el sustento a sus hogares, mientras que otras se desplazan para estudiar, ya que en zonas como Caño Negro no hay instituciones educativas de secundaria (Carazo 2016; Humbert y Braßel 2016).
9. Entrevista anónima a un vecino de Los Chiles, 15 de abril del 2017. 
La fuerza laboral en los monocultivos está conformada en su mayoría por hombres entre los 18 y 50 años, la mayoría de los cuales son reclutados en las empresas mediante contratos escritos establecidos por tiempo indefinido y en los cuales no se indica condiciones. Además, en muchos casos aparecen los "contratistas", que fungen como intermediarios entre la empresa y el trabajador, lo cual les permite a las agroindustrias librarse de las responsabilidades patronales con los asalariados (Carazo, 2016).

\section{Gráfico 6. Población sin seguro social y con analfabetismo en Los Chiles, Upala y Guatuso, Costa Rica (1963-2011)}

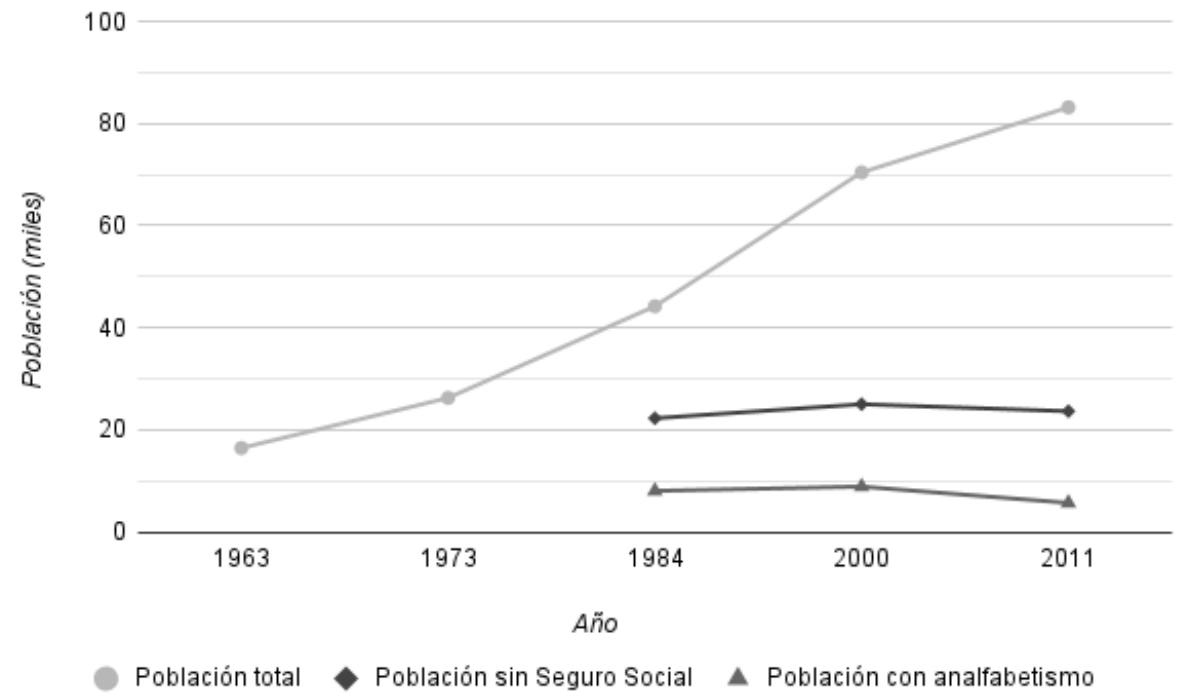

Elaboración propia con datos del CCP (2017) y los censos de 1963, 1973, 1984, 2000 y 2011.

De 1984 al 2011, el número de individuos no asegurados ha pasado de 22 291 a 23 665. El gráfico 6 permite contrastar que a pesar del crecimiento en exportaciones de las empresas piñeras y naranjeras que convierten a la ZNN en una de las más productivas, no se traduce en una cobertura educativa y de salud total, ya que se evidencia que la población sin seguro social aún sigue estando por encima de las 20 mil personas y el analfabetismo continúa presente, con reducciones mínimas. No solo representa una gran frustración para quienes sufren tal situación, sino que es un tema de exclusión y que podría favorecer aún más el incumplimiento de derechos laborales por parte de las compañías.

Los trabajadores del sector agropecuario se encuentran en una situación de inequidad salarial con respecto a lo establecido por ley, ya que, por ejemplo, en la mayoría de casos los trabajadores no cuentan con oportunidades de organización sindical y el pago a los trabajadores piñeros es semanal; perciben pago únicamente por los días efectivamente laborados, además de la cuestión de la salud (Segura Hernández y Ramírez Mora 2015). 
El cuarto aspecto para la conformación de correlaciones entre la producción piñera y naranjera, se encuentra la acumulación de capital en pocas manos. Es evidente que las elites que forman parte de estas compañías no solamente son económicamente poderosas, sino que también ejercen influencias muy significativas dentro de los aparatos estatales de los países. Los ingresos son superiores si se toman en cuenta los oligopolios que se han conformado y sus redes de poder en la región.

\section{Ni naranja ni piña: resistencias desde la organización comunitaria}

El escenario productivo de la ZNN presenta serias limitaciones para atender las necesidades de la población del territorio; más bien, en muchas ocasiones deviene en explotación laboral y afectación a la salud tanto humana como animal y ambiental. Ante este panorama, han surgido experiencias de organización comunitaria que aspiran a la construcción de alternativas de subsistencia y desarrollo.

A modo ilustrativo, se menciona el caso del colectivo Cosa, el cual ha estado acompañando desde el 2015 el proceso de organización de El Sitio y Las Flores de Caño Negro. Esta pequeña comunidad de aproximadamente 20 hogares está compuesta por gente que, en su mayoría, trabaja en plantaciones de monocultivos. Entonces, en función de las limitadas condiciones socioeconómicas, se han generado intervenciones desde diversas áreas de conocimiento. Se pretende, pues, alcanzar un nivel de organización que permita la ejecución de alternativas económicas para reducir la dependencia de la agroindustria.

A esta ejecución de alternativas se suman la agroecología, la economía, el arte y la educación. Según Altieri y Toledo (2010), la "revolución agroecológica" está basada en la transformación epistemológica, técnica y social para incidir en las mejoras ambientales, políticas y económicas de las personas, en la que la agricultura campesina ${ }^{10}$ desempeña una función sumamente importante.

Se ha trabajado, asimismo, en la conformación de sistemas de economía solidaria, la cual se caracteriza por promover la creación de organizaciones que enlacen la gestión de la actividad económica con el tejido social de donde surgen, desde los enfoques de autogestión, cooperación y solidaridad. Además, prevé respaldar la seguridad de los medios de producción mediante una construcción democrática, inclusiva y participativa en los procesos económicos (Pérez y Etxezarreta, 2015).

Sin embargo, en las propuestas de Altieri y Toledo (2010), y Farah y VasapoIlo (2011), por mencionar dos, para cada caso específico deben profundizarse las dificultades enfrentadas por los agricultores que se resisten a transformar sus métodos tradicionales. Se trata del acceso a la información, ${ }^{11}$ el burocratismo, las afectaciones de plagas, los agrotóxicos, los organismos transgénicos, las sequías, las inundaciones y demás factores que inciden sobre la productividad y muchas veces, motivan el uso de agrotóxicos y al abandono de la tierra.
10. La agricultura campesina -basada en policultivos, sistemas agroforestales, manejo natural de plagas, uso de semillas criollas, entre otros-, fue sustituida en gran parte por la agricultura industrial; sin embargo, ante las situaciones

contemporáneas, la agricultura campesina en resistencia ha ido adaptándose a las situaciones climáticas contemporáneas, acudiendo a la consulta del invaluable patrimonio de las prácticas agrícolas ancestrales indígenas (Altieri y Toledo, 2010).

11. El proceso de aprendizaje permeado de contexto mediante la práctica es parte de las bases de la educación popular implementada en El Sitio y Las Flores. 
12. "[S]e centra en la autonomía local, los mercados locales, los ciclos locales de producción y consumo, y las redes de agricultor a agricultor que promueven innovaciones e ideas agroecológicas que conlleva la soberanía tecnológica y energética dentro de un contexto de resiliencia" (Altieri y Toledo, 2010, p. 194).

13. Ver artículo de opinión «Actividad piñera y ambiente», publicado por el ministro de Agricultura, Luis Felipe Arauz, en el periódico La Nación del 15 de junio del 2017.
La puesta en práctica de estas alternativas ha sido un imotor primordial de emancipación de pueblos latinoamericanos que luchan cada vez más fuerte contra el gran aparato estatal y el poder empresarial, sobre todo en zonas rurales. Tales iniciativas favorecen poseer espacios para llevar a cabo prácticas dirigidas hacia la búsqueda de soberanía alimentaria ${ }^{12}$ y laboral, como forma de resistencia al sistema que presiona sobre las poblaciones y los recursos.

\section{Conclusiones y aperturas}

Una de las premisas centrales del pensamiento neoliberal radica en el repliegue de la injerencia del Estado sobre el mercado. Bajo esta perspectiva, se postula la necesidad de dejar fluir libremente las fuerzas del mercado. Sin embargo, gracias al estudio del aparato productivo de la piña y de la naranja en la ZNN, se ha constatado que tal repliegue del Estado no se presentó como tal, sino que simplemente se modificó la orientación de la intervención estatal, restringida a cumplir labores sumamente delimitadas y accesorias, centradas en la prestación de ciertos servicios básicos y en la aprobación de proyectos.

Esa transformación en el desempeño del Estado ha provocado un cambio en la forma en la que se concibe y practica el desarrollo rural y agrícola: durante la segunda mitad del siglo XX, se pasó de brindar apoyo técnico y financiero a los pequeños y medianos productores, quienes cosechaban tanto para autoconsumo como para el abastecimiento nacional de granos y legumbres, hacia la generación de un "buen clima de negocios" para la consolidación del nuevo modelo agroindustrial signado por los monocultivos.

Es simplista y erróneo achacarle solo a los monocultivos el estancamiento de la ZNN en cuanto al Desarrollo Humano. No obstante, la conexión y el análisis de ambos fenómenos dan cuenta de la poca capacidad que ha tenido el modelo de desarrollo agrícola actual para impulsar procesos económicos que aligeren las adversas condiciones socioeconómicas que caracterizan a la ZNN. A esto se suma el apoyo que la administración Solís le ha brindado a la producción y expansión piñera ${ }^{13}$ que junto a la inversión extranjera como supuesta forma de erradicación de la pobreza, da cuenta de lo arraigado que se encuentra, dentro del Estado las fuerzas y grupos económicos que apuestan a la agroindustria.

La expansión de los monocultivos -especialmente el piñero- se ha posicionado como una de las principales problemáticas socioambientales que Costa Rica enfrenta actualmente. Como consecuencia, es un tema que requiere ser estudiado con profundidad, por lo cual se opta por cerrar este artículo con una serie de aperturas investigativas. En primer lugar, se considera pertinente analizar, en clave histórica, la evolución de las condiciones socioeconómicas de la ZNN durante la segunda mitad del siglo XX, a fin de estudiar las conexiones entre esta evolución y los distintos modelos de desarrollo rural en la zona.

En segundo lugar, resulta importante atender que uno de los argumentos esgrimidos por quienes defienden los monocultivos, es que estas generan he- 
rramientas de desarrollo económico y social a través de numerosos empleos y contribución al fisco costarricense, a través del pago de impuestos. Sin embargo, es importante someter esta aseveración a escrutinio, considerando que las empresas no pagan impuestos de exportación, únicamente impuesto sobre la renta, pero que como ya se evidenció, muchas veces utilizan la banca offshore para mover sus ganancias hacia paraísos fiscales.

En tercer lugar, es importante poner la mirada sobre la operación de los procesos de certificación de calidad en las plantaciones de la ZNN, que son la supuesta garantía de la calidad y cumplimiento de estándares ambientales y laborales. Un estudio de redes de poder entre estas certificadoras puede esclarecer la legitimidad de estas.

\section{Agradecimientos}

A la Vicerrectoría de Acción Social de la Universidad de Costa Rica por el apoyo y financiamiento para el proyecto que impulsa este trabajo. También al equipo de Cosa por los valiosos aportes.

\section{Bibliografía}

Acevedo, Heiner y Mauricio Zamora (eds.). 2011. Refugio Nacional de Vida Silvestre Mixto Caño Negro: Plan de Manejo. San José: Sinac.

Almeida, Paul. 2016. Neoliberalismo y movimientos populares en Centroamérica. San Salvador: UCA Editores.

Altieri, Miguel y Víctor Manuel Toledo. 2010. «La revolución agroecológica de América Latina: Rescatar la naturaleza, asegurar la soberanía alimentaria y empoderar al campesino». El Otro Derecho 42: 163-202.

Aravena Bergen, Javiera. 2005. La expansión piñera en Costa Rica: La realidad de los perdedores de la agroindustria exportadora de la piña. San José: COECOCeiba.

Asamblea Legislativa de la República de Costa Rica. 2017. Comisión Especial Investigadora, que se dedique a analizar la información hecha pública a partir de la investigación periodística internacional en torno al bufete panameño Mossack Fonseca, con el fin de identificar mecanismos o prácticas utilizadas para eludir o evadir tributos, así como las diferencias vacíos y omisiones que pueda tener la legislación 
costarricense para la adecuada fiscalización y recaudación tributarias. Expediente No. 19973. San José: Asamblea Legislativa de Costa Rica. Baltodano, Javier. 2002. Resistiendo la pobreza, pérdida de biodiversidad y otros impactos del neoliberalismo en Costa Rica. En: Friends of the Earth International y World Rainforest Movement. Resistencia fecunda en los bosques. Comunidades locales en defensa de la biodiversidad forestal. Montevideo: World Rainforest Movement.

Baltodano, Javier e Isaac Rojas. 2005. «10 años de ecologismo: soñando y empujando». Ambientico 136: 11-12.

Barrientos, Orlando y Guisella Chaves. 2008. Región Huetar Norte. Oferta exportadora actual y oferta potencial de productos agropecuarios alternativos. San José: Sepsa-Procomer.

Black, Bob. 2013. La abolición del trabajo. Logroño: Pepitas de Calabaza.

Bloomberg. 2017. «Tampa Juice Service Inc». Bloomberg. Acceso 20 de abril de 2017.https://goo.gl/DujsB8

Boeglin, Nicolás. 31 de marzo de 2015. «La piña de Costa Rica ante la Comisión Interamericana de Derechos Humanos». Global Research. Acceso 20 de abril de 2017.https://goo.gl/5gcDcRb

Brenes Prendas, Steven y Renán Agüero Alvarado. 2007. «Reconocimiento taxonómico de arvenses y descripción de su manejo, en cuatro fincas productoras de piña (Ananas comosus L.), en Costa Rica». Agronomía Mesoamericana 18(2): 239-246.

Cadexco (Cámara de Exportadores de Costa Rica). 2017. «Sobre nosotros». Cámara de Exportadores de Costa Rica. Acceso 26 de agosto de 2017. https://goo.gl/72qHZw

Canapep (Cámara Nacional de Productores y Exportadores de Piña). 2017a. «¿Quién es Canapep?». Canapep. Acceso 26 de agosto de 2017. https://goo.gl/nUX5M2

Canapep (Cámara Nacional de Productores y Exportadores de Piña). 2017b. «Exportación a China podría aumentar en un 31\%». Revista Piña de Costa Rica 25: 18. 
Carazo, Eva. 2016. Condiciones de producción, impactos humanos y ambientales en el sector piña en Costa Rica. San José: Oxfam.

CCP (Centro Centroamericano de Población). 2017. «InfoCensos». Centro Centroamericano de Población. Acceso 09 de junio de 2017. https://goo.gl/vFjDOO

Central America Data. 31 de julio de 2014. «Compra y capitalización de firma agrícola costarricense». Central America Data. Acceso 21 de mayo de 2017.https://goo.gl/ZdeSnH

Chavarría Hernández, David. 01 de agosto de 2012a. «Diez piñeras acumulan $\$ 276$ millones de deuda con la Caja». Semanario Universidad. Acceso 15 de abril de 2017._https://goo.gl/R3VHU4

Chavarría Hernández, David. 03 de octubre de 2012b. «Representante legal de Mallon Oil es el fiscal de sociedades que poseen 136 millones de m2 en zona norte». Semanario Universidad. Acceso 09 de junio de 2017.https://goo.gl/A3iGSY

Chávez Trigueros, Abel. 2016. «La industria de la piña: Motor económico y social de Costa Rica». Revista Piña de Costa Rica 23: 4-5.

Chávez Trigueros, Abel. 2017. «Incae respalda labor social y ambiental del sector piñero». Revista Piña de Costa Rica 25: 4.

Corrales Brenes, Gerardo. 2017. «Importancia del tipo de cambio para el sector exportador». Revista Piña de Costa Rica 25: 10.

Cortés Ramos, Alberto. 2003. «Apuntes sobre las tendencias migratorias en América Central en la segunda mitad del siglo XX». Rev. Reflexiones 82(2): 31-45.

de Jaude, Marije van Lidth. 2005. La población migrante rural en Centroamérica. San José: Fida-Ruta.

Delgado Montoya, Edgar. 12 de febrero de 2010. «Alfredo Volio asume como presidente del Banco Nacional». El Financiero. Acceso 10 de abril de 2017.https://goo.gl/SHN6xp

Diario de Costa Rica. 10 de julio de 1935. «Siete mil piñas comprará este año la Fábrica Nacional de licores». Diario de Costa Rica. Acceso 20 de abril de 2017. https://goo.gl/ygkxOs 
Dubois, Vanessa, Jorge Mora, Francisco Parrado y Andrés Mora. 2016. Condiciones de producción, impactos humanos y ambientales en el sector de la piña en Costa Rica. San José: Asociación Regional Centroamericana para el Agua y el Ambiente.

Earth. 2004. Perfil del producto: naranja. Guácimo: Centro para la Formación Empresarial-Earth.

Escalera Reyes, Javier, Rafael Cáceres y Antonio Díaz Aguilar. 2013. «"Las apariencias engañan". Conservación, sociedad local y relaciones de poder: El caso de Caño Negro (Costa Rica)». Revista de Antropología Iberoamericana 8(3): 369-394. DOI: 10.11156/aibr.080306

Estado de la Nación. 2016. Vigésimosegundo Informe Estado de la Nación en desarrollo humano sostenible. San José: Programa Estado de la Nación.

Fallas Baldí, Oscar. 1994. Modelos de desarrollo y crisis ambiental en Costa Rica. San José: Asociación Ecologista Costarricense.

Fao (Food and Agriculture Organization of the United Nations). 2017. «Crops and livestock products». Fao. Acceso 10 de febrero de 2017. https://goo.gl/AhQeFM

Farah, Ivonne y Luciano Vasapollo. 2011. ¿Vivir bien? Paradigma no capitalista. La Paz: CIDES-UMSA.

Faure, Guy y Mario Samper. 2004. «Veinte años de apertura económica: el porvenir comprometido de la agricultura familiar en el norte de Costa Rica». Anuario de Estudios Centroamericanos 30(1-2): 7-26.

Fernández Morera, Alejandra y Antonio Jiménez Rueda. 03 de abril de 2016. «Cinco firmas tramitaron tres de cada cuatro transacciones con Mossack Fonseca». Database. Acceso 10 de marzo de 2017. https://goo.gl/uwXqvm

Ferrari, Marcela. 2010. «Prosopografía e historia política. Una aproximación». Antíteses 3(5): 529-550.

Flórula Digital de La Selva. 2017. «Flórula Digital de La Selva». Organización para Estudios Tropicales. Acceso 10 de mayo de 2017. https://goo.gl/3zdjPa 
Fonseca, Elizabeth. 2013. Centroamérica: Su historia. San José: Editorial UCR.

González, Paulino. 1976. Ruta Sarapiquí. Historia socio-política de un camino. San José: Avance de Investigación №15, Instituto de Investigaciones sociales, Universidad de Costa Rica.

González, Víctor. (Coord.). 2014. Costa Rica: Orange Juice Production and Trade. San José: Grain Report.

Granados, Carlos, Alonso Brenes y Luis Pablo Cubero. 2005. «Los riesgos de la reconversión productiva en las fronteras centroamericanas: el caso de la Zona Norte de Costa Rica». Anuario de Estudios Centroamericanos 31: 93-113.

Guereña, Arantxa. 2016. Desterrados: Tierra, poder y desigualdad en América Latina. Washington: Oxfam.

Guevara, Andrés, Ronald Arce y Porfirio Guevara. 2017. Impacto Económico, Social y Ambiental de la Piña en Costa Rica. San José: Incae-CLACDS. Gutiérrez, Isabel y Jackeline Siles. 2009. Diagnóstico de medios de vida y capitales de la comunidad de Humedales de Medio Queso, Los Chiles, Costa Rica. Moravia: UICN-Catie.

Harvey, David. 2003. The New Imperialism. Oxford: Oxford University Press.

Harvey, David. 2005. A produção capitalista do espaço. São Paulo: Annablume.

Herrera Flores, Joaquín. 2008. «La complejidad de los Derechos Humanos. Bases teóricas para una redefinición contextualizada». Revista Internacional de Direito e Cidadania 1: 103-135.

Humbert, Franziska y Frank Braßel. 2016. Süße Früchte, bittere Wahrheit. Die Mitverantwortung deutscher Supermärkte für menschenunwürdige Zustände in der Ananas- und Bananenproduktion in Costa Rica und Ecuador. Oxford: Oxfam Deutschland.

IICA (Instituto Interamericano de Ciencias Agrícolas). 2004. Frutas. Managua: IICA.

Jiménez Acuña, José Francisco. 2012. Cadena agroalimentaria de cítricos. Puriscal: Ministerio de Agricultura y Ganadería. 
La República. 19 de diciembre de 2016. «Upala Agrícola. El mayor empleador del cantón de Upala». La República. Acceso 18 de agosto de 2017.https://goo.gl/xv36Qw

La República. 24 de enero de 1976. «Banco Central de Costa Rica anuncia (...)». La República. Acceso 18 de abril de 2017.https://goo.gl/TB5s8w Leakey, Richard y Roger Lewin. 1998. La sexta extinción. El futuro de la vida y de la humanidad. Barcelona: Tusquets Editores.

León Araya, Andrés. 2015. Desarrollo geográfico desigual en Costa Rica. San José: Editorial UCR.

Llaguno Thomas, José Julián; Gerardo Cerdas Vega y Carlos Aguilar Sánchez. 2014. Transformaciones y continuidades en el capitalismo agrario centroamericano: el caso de Costa Rica. En: Almeyra, Guillermo; Luciano Concheiro Bórquez; João Márcio Mendes Pereira y Carlos Walter Porto-Gonçalves. (coords.). Capitalismo: Tierra y poder en América Latina (1982-2012). Costa Rica, Cuba, El Salvador, Guatemala, Honduras, México, Nicaragua. (Volumen III). Buenos Aires: Ediciones Continente.

Madrigal, Luis Manuel. 04 de abril de 2016. «Involucran a padre de exministro en plan para evadir impuestos». El Mundo.cr. Acceso 01 de mayo de 2017._https://goo.gl/XIsYDI

Monsalve Suárez, Sofía y María Silvia Emanuelli. s.f. Monocultivos y Derechos Humanos. Guía para documentar violaciones al derecho a la alimentación y a la vivienda adecuadas, al agua, a la tierra y el territorio relacionadas con los monocultivos para la producción agrícola industrial. México DF: FIAN \& HIC-AL.

Montiel Segura, Marco Antonio. 2015. «Uso de agroquímicos en la producción intensiva de piña en Costa Rica». Pensamiento Actual 15(25): 183-195.

Mora Alfaro, Jorge. 1994. Costa Rica: política agrícola y apertura económica en los años noventa. (Tesis de maestría en Política Económica). Universidad Nacional, Heredia, Costa Rica. 
Morelli, Keith. 18 de noviembre de 2015. «Tampa citrus exec Phil Tope among four killed in Nicaragua helicopter crash». Tampa Bay Times. Acceso 02 de mayo de 2017.https://goo.gl/qvYYfF

Pérez, Juan Carlos y Enekoitz Etxezarreta. 2015. «Sobre el concepto de economía social y solidaria: Aproximaciones desde Europa y América Latina». Revista Económica Mundial 40: 123-144.

Petras, James y Henry Veltmeyer. 2002. «Los campesinos y el Estado en América Latina: Un pasado turbulento, un futuro incierto». Problemas del Desarrollo 33(131): 7-64.

PNUD (Programa de las Nacionales Unidas para el Desarrollo). 2017. «Alajuela». PNUD-UCR. Acceso 15 de mayo de 2017. https://goo.gl/yFWwhG

Procomer (Promotora de Comercio Exterior de Costa Rica). 2016. «Estadísticas de Comercio Exterior. Costa Rica 2016. Exportaciones e importaciones.» Procomer. Acceso 26 de agosto de 2017. https://goo.gl/jx8vph

Quijandría, Gabriel; Javier Berrocal y Lawrence Pratt. 1997. La Industria de la piña en Costa Rica. Análisis de Sostenibilidad. San José: Incae.

Quirós Arias, Lilliam. 2001. «Integración de la producción de naranja en espacios rurales». Perspectivas Rurales 9: 175-193.

Rojas, José Enrique. 29 de abril de 2007. «Alfredo Volio Jiménez». La Nación. Acceso 18 de agosto de 2017._https://goo.gl/YecESG

Rojas, Ronny. 04 de abril de 2016. «Evadir impuestos sin disimulo, la intención de un empresario costarricense». Univisión. Acceso 10 de mayo de 2017. https://goo.gl/oFDyq1

Rosales, Auxiliadora y Uriel Naum Ávila. 2014. «El cautivador de los viajeros». Forbes. Acceso 21 de abril de 2017. https://goo.gl/NZBLrH

Samper, Mario. (Comp.). 2005. Trayectorias y disyuntivas del agro en la Zona Norte de Costa Rica. San José: Instituto de Investigaciones SocialesUniversidad de Costa Rica.

Sasa, Kifah. 2017. Monitoreo de cambio de uso en paisajes productivos. San José: PNUD. 
Saxe Fernández, Eduardo. 2005. Colapso mundial y guerra. San José: Amo al Sur Editorial.

Secmca (Consejo Monetario Centroamericano). 2017. «Costa Rica: Estadísticas históricas». Secmca. Acceso 26 de agosto de 2017. https://goo.gl/jia3PC

Segura Hernández, Gabriela y Karla Ramírez Mora. 2015. «Entre surcos de piña: Resistiendo el tiempo esclavo en el monocultivo». Rev. Reflexiones 94(2): 11-23.

Setena (Secretaría Técnica Nacional Ambiental). 2016. «Proyecto cultivo de piña, oficinas administrativas y taller de mantenimiento, El Concho, expediente administrativo n. ${ }^{\circ}$ D1-17709-2016-Setena». Setena. Acceso 26 de agosto de 2017. https://goo.gl/JJ8NmK

Silvetti, Felicitas y Daniel Cáceres. 2015. «La expansión de monocultivos de exportación en Argentina y Costa Rica. Conflictos socioambientales y lucha campesina por la justicia ambiental». Mundo Agrario 16(32): 1-28.

Socialismo Hoy. 08 de marzo de 2017a. «Exportaciones Norteñas: Cambian de puesto a afiliados del sindicato y rebajan salario a la mitad». Socialismo Hoy. Acceso 21 de mayo de 2017. https://goo.gl/ZaNE6S

Socialismo Hoy. 15 de marzo de 2017b. «Urgente: Trabajadores de piñera Exportaciones Norteñas nuevamente en huelga». Socialismo Hoy. Acceso 20 de mayo de 2017.https://goo.gl/jLHEb9

Socialismo Hoy. 26 de enero de 2016. «Más de 800 trabajadores sin seguro social en fincas de Exportaciones Norteñas SA». Socialismo Hoy. Acceso 15 de abril de 2017. https://goo.gl/JWws8K

Socialismo Hoy. 28 de septiembre de 2015. «TicoFrut: La explotación de trabajadores y el millonario negocio de tres países». Socialismo Hoy. Acceso 10 de junio de 2017. https://goo.gl/uxWfSt

Solórzano, William. 2004. La colonización agrícola de la Región Huetar Norte de Costa Rica 1884-1995. (Tesis de maestría en Historia), Universidad de Costa Rica, San Pedro, Costa Rica. 
TSE (Tribunal Supremo de Elecciones). 2010. «Contribuciones a los partidos políticos. Periodo electoral 2006-2010». TSE. Acceso 26 de agosto de 2017.https://goo.gl/AnN6Q7

TSE (Tribunal Supremo de Elecciones). 2014. «Contribuciones a los partidos políticos. Periodo electoral 2014-2018». TSE. Acceso 26 de agosto de 2017.https://goo.gl/BU8Es4

Valverde, Jaime. 2011. Desarrollo local en la región Huetar Norte Norte. San José: Cudeca y Uned.

Veltmeyer, Henry y James Petras (Coords.). 2015. El neoextractivismo ¿Un modelo posneoliberal de desarrollo o el imperialismo del siglo XXI? México D.F.: Editorial Crítica.

Zevallos, Emilio. 2013. Agenda de Competitividad para la Región Huetar Norte: Caracterización Socioeconómica de la Región Huetar-Norte. San José: Meic. 